\title{
Relationships of Socioeconomic Level with Eating Behavior of Traditional Food among Adolescents
}

\author{
Nur Hafizah Muhammad \\ Muhammad Shahrim Ab. Karim \\ Mohhidin Othman \\ Hazrina Ghazali \\ Department of Food Service and Management, Faculty of Food Science and Technology, \\ 43400 Universiti Putra Malaysia (UPM), Serdang, Selangor, Malaysia \\ Email: izzah_8987@yahoo.com
}

\section{Doi:10.5901/mjss.2013.v4n11p13}

\section{Abstract}

Traditional food is never just about eating and fulfilling our biological needs; nevertheless it preserves the culture and tradition properties of a nation. Traditional food is known as representation of identity and embraces the components of cultural and heritage of a particular group of people in particular region. Malaysia has created distinctively traditional food based on the multi-ethnicity roots that lives together throughout the years such as Malay, Chinese and Indian communities. Presently, in this new and modern environment with economic prosperity of the country, young generation seems unappreciated the traditional food. They had been showered with Western fast food and other foreign foods, whereby traditional food is not their only option. Previous studies found socioeconomic level effects the eating behavior of traditional food, especially in adolescents. Therefore, this study aims to investigate the impact of socioeconomic level on adolescents' eating behavior of traditional food in Malaysia situation by implementing Theory of Planned Behavior (TPB) as a background theory. Self-administered questionnaire was distributed to 655 secondary school students by using cluster sampling technique. Multiple linear regression (MLR) results indicated adolescents belong to lower $(B=0.28)$ and middle $(B=0.46)$ socioeconomic level family have the capability to control their intention to eat traditional food; whereas adolescents came from high socioeconomic level proved to rely on their attitudes towards traditional food $(B=0.34)$ to drive the intention to eat traditional food.

Keywords: Socioeconomic level, Traditional food, Adolescents, Eating behavior, Malaysia

\section{Introduction}

\subsection{Traditional food in Malaysia}

EUROFIR defined traditional food as a food of special properties which clearly distinguished from other similar food products from same category in terms of the "traditional ingredients" (raw materials) used or "traditional composition" added or "traditional preparation and processing methods" applied in making the particular food (Tajkarimi, Ibrahim, \& Fraser, 2013). Moreover, Williams, Crockett, Harrison, and Thomas (2012) stated that traditional food served as repertoire of a country which portrayed the people's traditions, cultures, lifestyles plus eating behaviors of that nation. Historically, Malaysian traditional food is created from the multi-ethnicity that lived harmonically for years in Malaysia. Most of traditional food in Malaysia is well-influenced from the three major ethnics, who are Malays, Chinese and Indians.

Rice is staple food in Asian countries including Malaysia. Rice becomes the primary ingredient in daily meals and source for many traditional foods in Malaysia. Some Asian citizens are intensely emphasizing meals are not considered as meals without rice as main character (Franzen \& Smith, 2009). In Malaysia, a traditional meal composed of rice, vegetables and protein dishes which served during breakfast, lunch as well as dinner. Together with rice, local herbs and spices are added as flavor enhancer in the traditional fish or meat and vegetables dishes. Commonly used herbs and spices are lemongrass, Vietnamese mint, cilantro, curry leaves, turmeric, torch ginger flower; kafir lime leaves, tamarind and various types of herbs, wild roots and tree leaves that locally found such as "ulam raja", fern leaves, "pegaga", "daun kaduk", tapioca leaves and water spinach. Apart from being balanced diet meals, traditional food also stores beneficial 
nutrients required for maintaining body health and diminishes chronic diseases (Salleh, 2006). Some of traditional food in Malaysia such as "nasi lemak", "roti canai" and "char kuetiaw" are getting more popular, particularly in Asia regions. Few Malaysian's restaurants and food festival in other countries indirectly promote the traditional food to world. Consequently, many tourists came to Malaysia just for the gastronomic reasons and they found that Malaysian traditional food is nice, tasty, reasonable price; besides freshly prepared and healthy (Jalis, Mohd Zahari, Zulkifly, \& Othman, 2009).

\subsection{Changes in socioeconomic level}

Socioeconomic level sets as indicators of one's lifestyles included educational background, occupation and also household incomes of a family. People from different level of socioeconomic might experienced different ways of lifestyles. Obviously, the way of food consumption patterns and eating behavior of a person may determine largely from the socioeconomic background. For example, people from higher socioeconomic level are consumed more expensive food than others from moderate and low socioeconomic level (da Veiga \& Sichieri, 2006).

Like others developing countries in Asia, Malaysia undergoes several changes in industrialization, modern development, economic improvement and globalization as well. Thus, these changes enable the Malaysians to enjoy luxurious lifestyles with better education, job opportunities and more spending power today's, also known as the socioeconomic components. Simultaneously, eating behavior and food consumption patterns of Malaysians are also shifted from traditional to modern route, especially among young generations (Ganasegeran, et al., 2012).

\subsection{Adolescent's eating behavior}

Eating behavior is a complex series of behaviors, which includes the food choice, meal patterns (composition of food into meals), eating environments and after eating scenario (Yannakoulia, Ntalla, Papoutsakis, Farmaki, \& Dedoussis, 2010). Meanwhile, adolescence is a vulnerable period in human growth where an optimal diet with balanced nutrients must be adequate enough to support normal development of the body and avoid nutrition-related diseases (Ahn, Engelhardt, \& Joung, 2006). However, eating behavior among adolescents currently is changing to food composed of high fat, high sodium or high sugar such as cookies, candies, salty chips, and soft drinks) and low intake of fruits and vegetables (Fitzgerald, Heary, Kelly, Nixon, \& Shevlin, 2013). There are several factors that affecting adolescents' food choice, exclusively the food must be appealing, tasty, convenience, fast, available at all time and affordable by their pocket money (Meehan, Yeh, \& Spark, 2008).

Major contribution for eating behavior of adolescents is the socioeconomic level of the family. da Veiga and Sichieri (2006) revealed the eating behavior of young generations is fundamentally determined by the family background. For example, adolescents from high household incomes tend to have more spending power in buying food compare to their peers from low or moderate socioeconomic level. Additionally, family where both parents are working, family meals have become less traditional due to time restriction at workplace (Inglis, Ball, \& Crawford, 2005). So, the food consumed by adolescents is selected independently by them. In the similar vein, the parental control over their children food choice has been diminished with age. Older their children had become, the parents shown less concerned on the children's eating behavior (MacFarlane, Crawford, Ball, Savige, \& Worsley, 2007).

Besides that, educational whether informal or formal at home may directly furnish the adolescents eating behavior. Some adolescents are well-rehearsed by their parents about healthy eating and how to make the correct choice for food to eat. Particularly, high socioeconomic level's parents with higher educational level preferred modern healthy food choice with reduction of traditional healthy food (Delva, O'Malley, \& Johnston, 2007). As mention earlier, traditional food embraces not only good taste, yet it offers balanced nutrients meals for the eaters. It has been proven about $85 \%$ of adults are still practicing traditional diet; however, about $70 \%$ of adolescents have already shifting their eating behavior towards western diet in most of Asian regions (Ahn, Engelhardt, \& Joung, 2006).

\subsection{Eating behavior of traditional food}

Above all, it is an important issue to study in order to understand the adolescents' eating behavior and consumption patterns of traditional food in Malaysia nowadays. Due to globalization and economic prosperity, adolescents are overwhelmed by different kinds of food surrounding them and their current eating behavior is believed that they draw lots on the western food and snacks (Adnan \& Muniandy, 2012). Ironically, the Malaysia traditional food becomes less popular among adolescents. Many efforts had been done by the Malaysian government to promote traditional food 
throughout the world. Ministry of Foreign Affairs, Malaysia held a Malaysian traditional food festival at various countries in Europe such as England and Romania as their effort to promote traditional food to foreigners, meanwhile Department of Intangible Heritage, Malaysia proudly presented 100 Heritage Food in September 2009 to enhance the consumption of traditional food among tourists and specifically towards Malaysians. This situation had drawn attention to this study where the main objective of the study was to examine eating behavior of traditional food among adolescents from different socioeconomic level. The specific objectives for this study were listed as followed:

1. To record traditional food consumption patterns of adolescents at school, including the foods brought to school and foods purchased from school canteen and food stores (vendors, local restaurants, tuck shop) nearby the schools.

2. To investigate the differences in socioeconomic level of adolescents were related to the adolescents' intention to eat traditional food.

\section{Methodology}

\subsection{Design and sample}

The study was carried out in the state of Selangor, due to the highest population capacity in Malaysia (Department of Statistics, 2011). Using stratified sampling technique for the study, public secondary schools in Selangor had been divided into four zone based on the geographical area. There were east, west, north and south zones. Out of 357,571 registered secondary school students in Selangor, only 700 of them were selected to be the respondents for this study; where later, the amount assorted into population ratio for each zone. Yamane (1967) sample population formula was applied to calculate total amount of sample needed:

Sample size (n) by Yamane (1967),

$$
\begin{aligned}
& n=\frac{N}{1+N(e)^{2}} \\
& \text { Where, } \mathrm{N}=\text { Total population } \\
& \mathrm{e}=5 \% \\
& \mathrm{n}=\text { Sample size } \\
& n=\frac{357,571}{1+357,571(0.05)^{2}} \\
& \mathrm{n}=399.553=400 \text { respondents }
\end{aligned}
$$

From the formula, 400 respondents were necessary to gather the information about eating behavior of traditional food. However, additional two hundreds of respondents were hopefully able to obtain more persistence findings. The respondents were required to complete a self-administrated questionnaire designed to achieve the objective stated for the study. Eventually, 655 students aged from 15 to 19 years old had participated to fill up the questionnaire.

\subsection{Procedure}

Approval letters from Malaysia Ministry of Education and Selangor Department of Education as well as permission letter from Faculty Food Science and Technology, Universiti Putra Malaysia (UPM) were obtained prior to data collection process. Self-administered questionnaire used as instrument was distributed to the secondary students through the assigned teachers by principal. All the data collection was performed on October 2012 and completed at the end of the month.

\subsection{Instrument}

Six sections of self-administered questionnaire were designed that extracted the information about respondents' (1) attitudes towards traditional food, (2) social influential parties and (3) perceived behavioral control on eating traditional food, (4) intention to eat traditional food; and (5) traditional food consumption patterns and lastly (6) demographic profile. The questionnaire was adopted from various questionnaires in eating behavior studies. As backbone structure of the instrument, Theory of Planned Behavior variables by Icek Ajzen (1991) were implemented as dependent and independent variables of this study. Shepherd and Dennison (1996) mentioned that this theory had been well-applied across wide range of human behaviors, especially eating behaviors and food choices studies. 


\subsection{Statistical analyses}

Basically, the questionnaires were assorted out into three socioeconomic level set by the Malaysia Department of Statistic in 2010 comprised of low, medium and high household incomes by using SPSS version 20. Particularly, respondents in low socioeconomic level categorized by below RM 1500 of their household incomes; whereas those came from moderate socioeconomic level approximately had RM 2000 till RM 4000 range of household income. However, respondents with RM 5000 and above household incomes were considered as high socioeconomic level. Similarly, all statistical analyses were also conducted by the SPSS program. For the first objective, descriptive statistic such as frequencies and percentage used to describe the consumption patterns of traditional food among respondents. Meanwhile, multiple linear regression (MLR) was used to figure out the most and least influential variable to determine the respondent's intention to eat traditional food. 95\% confidence interval was used for the MLR analyses where independent variables with $p<0.05$ only were accepted for the regression models

\section{Findings and Discussion}

\subsection{Respondents profile}

Table 1: Profile of respondents

\begin{tabular}{|c|c|c|c|}
\hline \multirow[t]{2}{*}{ Respondent's profile } & \multicolumn{3}{|c|}{ Household income } \\
\hline & Low & Moderate & High \\
\hline \multicolumn{4}{|l|}{ Race } \\
\hline Malay & 130 & 149 & 123 \\
\hline Chinese & 48 & 48 & 31 \\
\hline Indian & 25 & 21 & 14 \\
\hline Others & 6 & 0 & 2 \\
\hline \multicolumn{4}{|l|}{ Father's educational level } \\
\hline Elementary school & 24 & 11 & 2 \\
\hline Secondary school & 163 & 151 & 69 \\
\hline Diploma & 18 & 45 & 40 \\
\hline Degree & 5 & 10 & 39 \\
\hline Postgraduate & 1 & 4 & 25 \\
\hline \multicolumn{4}{|l|}{ Mother's educational level } \\
\hline Elementary school & 32 & 15 & 2 \\
\hline Secondary school & 156 & 150 & 66 \\
\hline Diploma & 14 & 42 & 47 \\
\hline Degree & 2 & 8 & 37 \\
\hline Postgraduate & 0 & 1 & 20 \\
\hline \multicolumn{4}{|l|}{ Father's occupation } \\
\hline Teacher / Academician & 1 & 4 & 15 \\
\hline Professional & 1 & 8 & 26 \\
\hline Executive / Manager & 4 & 24 & 64 \\
\hline Administration support / Clerical & 7 & 38 & 11 \\
\hline Protective / Security service & 13 & 21 & 11 \\
\hline Self-employed & 109 & 77 & 39 \\
\hline Unemployed & 5 & 2 & 1 \\
\hline Retired & 23 & 9 & 3 \\
\hline Others & 42 & 40 & 8 \\
\hline \multicolumn{4}{|l|}{ Mother's occupation } \\
\hline Teacher / Academician & 6 & 14 & 36 \\
\hline Professional & 0 & 2 & 13 \\
\hline Executive / Manager & 1 & 6 & 20 \\
\hline Administration support / Clerical & 12 & 24 & 22 \\
\hline Protective / Security service & 2 & 7 & 3 \\
\hline Self-employed & 29 & 38 & 16 \\
\hline Unemployed & 142 & 120 & 62 \\
\hline Retired & 3 & 3 & 2 \\
\hline Others & 9 & 9 & 3 \\
\hline
\end{tabular}


Table 1 described the respondent's profile according to their reported household income in the questionnaire. The sample consisted of 655 adolescent students with $93.57 \%$ response rate. 170 students were in high socioeconomic level; meanwhile about 209 and 218 adolescents were classified as low and moderate socioeconomic level, respectively. The race proportions for the sample represented precisely the ethnic ratios in Malaysia. Most of the students were Malays, Chinese, and Indians and minority ethnics. Apart from that, the majority of high educational level parents were belongs to high socioeconomic category with frequencies of 25 and 20 for fathers and mothers, correspondingly. Among all, parents' occupations of low socioeconomic were self-employed (109); while most of their spouses were full time housewives. Meanwhile, greater numbers of adolescent's fathers from moderate socioeconomic families were working as manager (24), administration support (38) and also self-employed (77) and similarly, about 120 mothers were housewives and had their some small business (38).

\subsection{Traditional food consumption patterns}

Overall, table 2 showed the traditional food consumption patterns of the adolescents. Only $20.6 \%$ of them eat traditional food more than five times per week. The highest percentage of traditional food intakes was three times a week; while there were adolescents (11.9\%) that only eat traditional food less than a time. $54.5 \%$ of adolescents enjoyed eating traditional food at home. Most of them felt that traditional food is a family meal and some of the food is not suitable to eat at school; so they felt comfortable to eat traditional food at home. Furthermore, during the school days, the adolescents usually bought traditional food at school canteen (55.4\%) and street stalls outside the school (22.3\%). Lastly, approximately $65.0 \%$ of adolescents did not bring food to school because they observed it as troublesome, especially among boys. They also stated that school canteen already prepared traditional food and their parents provided enough pocket money to them to buy from canteen. Differently, there were $31.6 \%$ of adolescents did bring traditional food to school. For them, they wanted to share with their friends, besides served as breakfast and energy booster in the morning. However, some of adolescents reported that their mothers always prepared traditional food for them to bring to school due to lack of money. Follow was the list of traditional food most commonly brought to school by the secondary students: "Nasi lemak", "Karipap", "Nasi goreng varieties", "Banana fritters", "Keropok lekor", "Tosai", "Kuih bulan", "Roti canai", "Bak kut teh" and "Nasi ayam".

Table 2: Consumption patterns of traditional food

\begin{tabular}{lcc}
\hline \hline & Frequency & Percentage (\%) \\
\cline { 2 - 3 } How often do you eat traditional food per week & 78 & 11.9 \\
Less than 1 time & 170 & 26.0 \\
2 times & 192 & 29.3 \\
3 times & 77 & 11.8 \\
4 times & 135 & 20.6 \\
More than 5 times & & \\
Where do you usually eat your traditional food & 357 & 54.5 \\
Home & 82 & 12.5 \\
Canteen & 121 & 18.5 \\
Street stalls & 81 & 12.4 \\
Local ethnic restaurant & 12 & 1.8 \\
Others & & \\
Where do you usually purchase traditional food during school days & 80 & 12.2 \\
Local ethnic restaurant & 363 & 55.4 \\
Canteen & 146 & 22.3 \\
Street stalls & 56 & 8.5 \\
Never & 8 & 1.2 \\
Others & & \\
Do you bring any traditional food from home to school & 207 & 31.6 \\
Yes & 426 & 65.0 \\
$\quad$ No & & \\
\hline \hline
\end{tabular}




\subsection{Differences of intention to eat traditional food for three level of socioeconomic}

Regression analyses were conducted to figure out the contribution of each variable for all level of socioeconomic and the present findings explained in table 3 for low, table 4 for moderate and table 5 for high socioeconomic level based on their household income. The three variables adapted from Theory of Planned Behavior showed significant results for all regression models $(p<0.05)$.

Table 3: Regression model for low household income

\begin{tabular}{|c|c|c|c|c|c|}
\hline \multicolumn{6}{|c|}{ Low household income } \\
\hline \multirow[t]{2}{*}{ Variables } & \multicolumn{2}{|c|}{ Unstandardized Coefficients } & $\begin{array}{l}\text { Standardized } \\
\text { Coefficients }\end{array}$ & \multirow[t]{2}{*}{$\mathrm{t}$} & \multirow[t]{2}{*}{ Sig. $t$} \\
\hline & Beta & Std. Error & Beta & & \\
\hline Constant & 0.14 & 0.33 & & 0.43 & 0.67 \\
\hline Attitudes towards traditional food & 0.43 & 0.11 & 0.27 & 3.81 & 0.00 \\
\hline Social norms & 0.24 & 0.08 & 0.20 & 2.92 & 0.00 \\
\hline Perceived behavioral control & 0.36 & 0.09 & 0.28 & 4.11 & 0.00 \\
\hline$F=49.03 \quad($ Sig. $=0.00)$ & 1 & & 0 & $\operatorname{std}$ & 055 \\
\hline
\end{tabular}

a. Dependent Variable: Intention to eat traditional food

Table 4: Regression model for moderate household income

\begin{tabular}{|c|c|c|c|c|c|}
\hline \multicolumn{6}{|c|}{ Moderate household income } \\
\hline \multirow[t]{2}{*}{ Variables } & \multicolumn{2}{|c|}{ Unstandardized Coefficients } & $\begin{array}{l}\text { Standardized } \\
\text { Coefficients }\end{array}$ & \multirow[t]{2}{*}{$\mathrm{t}$} & \multirow[t]{2}{*}{ Sig. t } \\
\hline & Beta & Std. Error & Beta & & \\
\hline Constant & -0.38 & 0.31 & & -1.23 & 0.22 \\
\hline Attitudes towards traditional food & 0.39 & 0.09 & 0.24 & 4.13 & 0.00 \\
\hline Social norms & 0.16 & 0.07 & 0.13 & 2.25 & 0.03 \\
\hline Perceived behavioral control & 0.61 & 0.08 & 0.46 & 7.47 & 0.00 \\
\hline \multicolumn{6}{|l|}{$F=72.39 \quad($ Sig. $=0.00)$} \\
\hline $\mathrm{R}=0.70$ & $\mathrm{R}^{2}=0.49$ & Adjus & $2=0.49$ & Std. $\epsilon$ & $=0.49$ \\
\hline
\end{tabular}

a. Dependent Variable: Intention to eat traditional food

Table 5: Regression model for high household income

\begin{tabular}{|c|c|c|c|c|c|}
\hline \multicolumn{6}{|c|}{ High household income } \\
\hline \multirow[t]{2}{*}{ Variables } & \multicolumn{2}{|c|}{$\begin{array}{l}\text { Unstandardized } \\
\text { Coefficients }\end{array}$} & \multirow{2}{*}{$\begin{array}{c}\text { Standardized } \\
\text { Coefficients }\end{array}$} & \multirow[t]{2}{*}{$t$} & \multirow[t]{2}{*}{ Sig. t } \\
\hline & Beta & Std. Error & & & \\
\hline Constant & -0.59 & 0.32 & & -1.83 & 0.07 \\
\hline Attitudes towards traditional food & 0.52 & 0.11 & 0.34 & 4.92 & 0.00 \\
\hline Social norms & 0.26 & 0.08 & 0.22 & 3.42 & 0.00 \\
\hline Perceived behavioral control & 0.42 & 0.09 & 0.31 & 4.77 & 0.00 \\
\hline $\begin{array}{l}F=64.18 \quad(\text { Sig. }=0.00) \\
R=0.73\end{array}$ & $R^{2}=0.53$ & Adju & $R^{2}=0.52$ & Std. & 0.49 \\
\hline
\end{tabular}

a. Dependent Variable: Intention to eat traditional food

Intention to eat traditional food among adolescents from low and moderate socioeconomic level strongly associated by perceived behavioral control variable (low SEL: $B=0.28$ and moderate SEL: $B=0.46$ ). Perceived behavioral control explained as one's perceptions of control over eating traditional food and also the obstacles and easiness to attend that behavior (Shepherd \& Dennison, 1996). This indicated that low and moderate adolescents had capabilities to control their own intention to eat traditional food without outside influences such from the parents and friends. However, adolescents from high socioeconomic level mainly depended on their attitudes towards traditional food $(B=0.34)$ in order 
to light up the intention to eat. Attitudes on traditional food represent as overall evaluation of adolescent over the food includes the sensory appeal, emotion, knowledge, appreciation and health concern (Benarroch, Perez, \& Perales, 2011). Generally, social influences from parents and peers were the least contributors to enhance adolescents' intention to eat traditional food for all socioeconomic groups. It contributed $B=0.20$ for low $S E L, B=0.13$ for moderate $S E L$ and $B=$ 0.22 for high SEL.

Living area of the adolescents played an important role in determining the intention to eat traditional food. Low and moderate socioeconomic level families usually lived in rural and suburban area of the country. They had been exposed to the traditional food since childhood and due to lack of money, they seem to choose traditional food because it is cheaper and affordable for them buy (Temple, Steyn, Myburgh, \& Nel, 2006; Jalis, Mohd Zahari, Zulkifly, \& Othman, 2009). Moreover, without availability to other kind of food, traditional food became that adolescent's favorite food in terms of taste, appearance and price (Riggio, Valenzuela, \& Weiser, 2010). Contradictory, high socioeconomic level families were living in the centre of the metropolitan area where they surrounded by various types of modern foods such as fast food and traditional food of other countries likes sushi from Japan. With accessibility and enough money in hand, high socioeconomic adolescents managed to pay for non-Malaysian traditional food. Previous literature supported that adolescents lived near fast food restaurants were often eating from those restaurants (Forsyth, Wall, Larson, Story, \& Neumark-Sztainer, 2012).

Another possibility of the differences in eating behavior of traditional food among different socioeconomic adolescent was the family practices at home. Previously, adolescents felt that traditional food is family meals where they often ate it at home. Besides giving the parents chance to control their children eating behavior, family meals also applied beneficial time for useful conversation within family members. Additionally, parents who shared the knowledge about the food, family history and culture resulted to have knowledgeable, higher self-esteem and greater admiration children of their background (Fruh, Fulkerson, Mulekar, \& Clanton, 2011). From the result (table 1), higher household income closely related to higher occupation rank such as professional, academician and self-employed parents. Consequently, with both parents were working, family meals became less traditional due to limited preparation time. The mothers were choosing more convenience and quick food for the family and fast food take away usually pop up as easiest food choices (Adnan \& Muniandy, 2012). If compare to low and moderate socioeconomic level adolescents, most of their mothers were fulltime housewives who prepared every meal at home. Likewise, those adolescents mentioned that their mothers loved to cook traditional food and packed traditional food in lunch box for them to bring to school.

Majority of parents from high socioeconomic level had better educational status. Nevertheless, higher educational level parents did not assured to have children that adored traditional food. Adnan and Muniandy (2012) proved that high intakes of fast food among children with higher educational level mothers. The most possible explanation to this situation was lack of nutrients knowledge and awareness of healthy foods as well as availability of those foods at home. On the other hand, high educational level parents appeared to have higher-quality diet and concerned to their children health (Tur, Puig, Benito, \& Pons, 2004). Even though they were aware of healthy diet of the children, but the parents preferred to choose modern healthy food and consumed less traditional healthy food. They believed traditional food is unhealthy and not suitable to their modern diets.

\section{Conclusion}

In Malaysia, socioeconomic of adolescents families may directly or indirectly effect the eating behavior of traditional food. Low and moderate socioeconomic adolescents were capable to control their intentions to eat traditional food; while high socioeconomic adolescents were depended on the overall perceptions of traditional food to decide their intention. Nevertheless, social influence from parents and friends was not the major contributor; however, family structure and home food environment of the adolescents known to be influenced the eating of traditional food (Lhuissier, et al., 2013). The close relationships between family members would shape adolescents' self-esteem, self-efficacy and eating behavior of traditional food (Berge, Wall, Larson, Loth, \& Neumark-Sztainer, 2013). Furthermore, availability and accessibility of traditional food at home and also in surrounding the neighborhood were shown to be forecaster of adolescents eating behavior (Kelly, Flood, \& Yeatman, 2011). Apart from that, findings reported that adolescent's diet in Malaysia seems to become less traditional. Majority numbers of adolescents ate traditional food at home only and they favored more modern food when dining out.

For years now, this study shines some light on the currently adolescent's eating behavior of traditional food. A better approach such as advertisement on the beneficial effect of traditional food should be done by responsible authorities on mass media, especially at school. Finally, sample size was the limitation of our study. Future research 
should increase the number of respondents and explore different angles of eating traditional food among adolescents in Malaysia.

\section{References}

Adnan, N., \& Muniandy, N. D. (2012). The relationship between mothers' eduactional level and feeding practices among children in selected kindergartens in Selangor, Malaysia: a cross-sectional study. Asian Journal of Clinical Nutrition, 4(2), 39-52.

Ahn, B. C., Engelhardt, K., \& Joung, H. (2006). Diet variety is associated with socio-economic factors. Ecology of Food and Nutrition, 45, 417-430.

Benarroch, A., Perez, S., \& Perales, J. (2011). Factors influencing adolescent eating behavior: application and validation of a diagnostic instrument. Electronic Journal of Research in Educational Psychology, 9(3), 1219-1244.

Berge, J. M., Wall, M., Larson, N., Loth, K. A., \& Neumark-Sztainer, D. (2013). Family functioning: Associations with weight status, eating behaviors, and physical activity in adolescents. Journal of Adolescent Health, 52, 351-357.

da Veiga, G. V., \& Sichieri, R. (2006). Correlation in food intake between parents and adolescents depends on socioeconomic level. Nutrition Research, 26, 517-523.

Delva, J., O'Malley, P. M., \& Johnston, L. D. (2007). Availability of more-healthy and less-healthy food choices in American Schools. American Journal of Preventive Medicine, 33(4), 226-239.

Department of Statistics, M. (2011). Population Distribution by Local Authority Areas and Mukims 2010. Putrajaya, Wilayah Persekutuan Putrajaya, Malaysia: Department of Statistics, Malaysia.

Fitzgerald, A., Heary, C., Kelly, C., Nixon, E., \& Shevlin, M. (2013). Self-efficacy for healthy eating and peer support for unhealthy eating are associated with adolescents' food intake patterns. Appetite, 63, 48-58.

Forsyth, A., Wall, M., Larson, N., Story, M., \& Neumark-Sztainer, D. (2012). Do adolescents who live or go to school near fast-food restaurants eat more frequently from fast-food restaurants? Health \& Place, 18, 1261-1269.

Franzen, L., \& Smith, C. (2009). Acculturation and environmental change impacts dietary habits among adults Hmong. Appetite, 52, 173-183.

Fruh, S. M., Fulkerson, J. A., Mulekar, M. S., \& Clanton, C. (2011). The suprising benefits of the family meals. The Journal for Nurse Practitioners, 7(1), 18-22.

Ganasegeran, K., Al-Dubai, S. A., Qureshi, A. M., Al-abed, A.-a. A., AM, R., \& Aljunid, S. M. (2012). Social and psychological factors affectig eating habits among university students in a Malaysian medical school: a cross-sectional study. Nutrition Journal, 11(48).

Jalis, M. H., Mohd Zahari, M. S., Zulkifly, M. I., \& Othman, Z. (2009). Malaysian gastronomic tourism products: assessing the level of their acceptance among the western tourists. South Asian Journal of Tourism and Heritage, 2(1), 31-44.

Kelly, B., Flood, V. M., \& Yeatman, H. (2011). Measuring local food environments: An overview of available methods and measures. Health \& Place, 17, 1284-1293.

Lhuissier, A., Tichit, C., Caillavet, F., Cardon, P., Masullo, A., Martin-Fernandez, J., .. Chauvin, P. (2013). Who still eats three meals a day? Findings from a quantitative survey in the Paris area. Appetite, 63, 59-69.

MacFarlane, A., Crawford, D., Ball, K., Savige, G., \& Worsley, A. (2007). Adolescent home food environments and socioeconomic position. Asia Pacific Journal of Clinical Nutrition, 16(4), 748-756.

Meehan, M., Yeh, M.-C., \& Spark, A. (2008). Impact of exposure to local food sources and food preparation skills on nutritional attitudes and food choices among urban minority youth. Journal of Hunger \& Environmental Nutrition, 3(4), 456-471.

Riggio, H. R., Valenzuela, A. M., \& Weiser, D. A. (2010). Household responsibilities in the family of origin: relations with self-efficacy in young adulthood. Personality and Individual Differences, 48, 568-573.

Salleh, H. (2006). Peoples and Traditions. Kuala Lumpur: Editions Didier Millet.

Shepherd, R., \& Dennison, C. M. (1996). Influences on adolescent food choice. Proceedings of the Nutrition Society, 55, 345-357.

Tajkarimi, M., Ibrahim, S. A., \& Fraser, A. M. (2013). Food safety challenges associated with traditional foods in Arabic speaking countries of the Middle East. Trends in Food Science \& Technology, 29, 116-123.

Temple, N. J., Steyn, N. P., Myburgh, N. G., \& Nel, J. H. (2006). Food items consumed by students attending schools in different socioeconomic areas in Cape Town, South Africa. Nutrition, 22, 252-258.

Tur, J. A., Puig, M. S., Benito, E., \& Pons, A. (2004). Associations between sociodemographic and lifestyle factors and dietary quality among adolescents in Palma de Mallorca. Nutrition, 20(6), 502-508.

Williams, J. D., Crockett, D., Harrison, R. L., \& Thomas, K. D. (2012). The role of food culture and marketing activity in health disparities. Preventive Medicine, 55, 382-386.

Yannakoulia, M., Ntalla, I., Papoutsakis, C., Farmaki, A.-E., \& Dedoussis, G. V. (2010). Consumption of vegetables, cooked meals, and eating dinner is negatively associated with overweight status in children. The Journal of Pediatrics, 157, 815-820. 